Braz J Med Biol Res, January 2012, Volume 45(1) 1-7

doi: 10.1590/S0100-879X2011007500166

\section{Epidemiology of recurrent venous thrombosis}

D.D. Ribeiro, W.M. Lijfering, S.M. Barreto, F.R. Rosendaal and S.M. Rezende

The Brazilian Journal of Medical and Biological Research is partially financed by

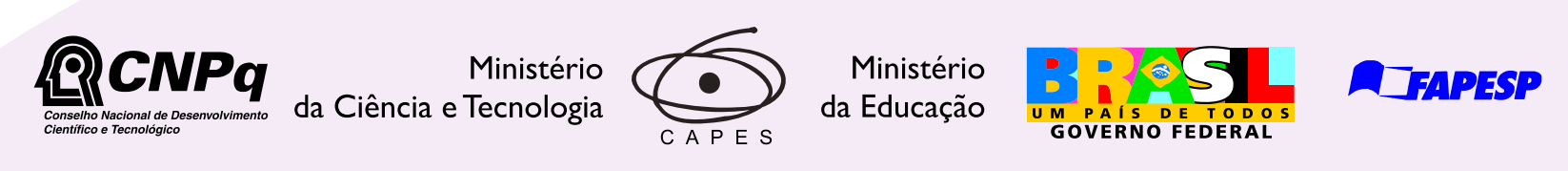

Institutional Sponsors
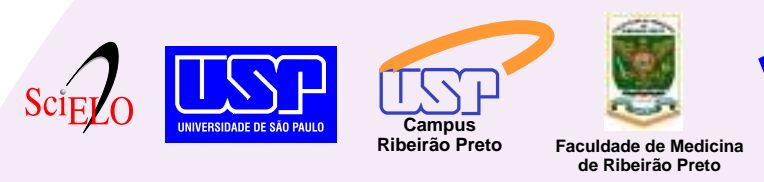

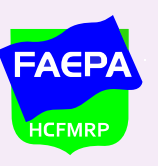

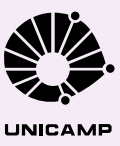

$\oplus$ SHIMADZU

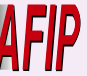

Associaçăo
Fundo
de Incentivo

Explore High - Performance MS Orbitrap Technology

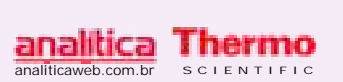




\title{
Epidemiology of recurrent venous thrombosis
}

\author{
D.D. Ribeiro ${ }^{1,2}$, W.M. Lijfering ${ }^{2}$, S.M. Barreto ${ }^{3}$, \\ F.R. Rosendaal ${ }^{2,4}$ and S.M. Rezende ${ }^{5}$ \\ ${ }^{1}$ Divisão de Hemostasia, Departamento de Hematologia, Universidade Federal de Minas Gerais, \\ Belo Horizonte, MG, Brasil \\ 2Department of Clinical Epidemiology, Leiden University Medical Center, Leiden, the Netherlands \\ ${ }^{3}$ Departamento de Saúde Pública, Universidade Federal de Minas Gerais, Belo Horizonte, MG, Brasil \\ ${ }^{4}$ Department of Thrombosis and Haemostasis, Leiden University Medical Center, Leiden, the Netherlands \\ ${ }^{5}$ Departamento de Clínica Médica, Universidade Federal de Minas Gerais, Belo Horizonte, MG, Brasil
}

\begin{abstract}
Venous thrombosis, including deep vein thrombosis and pulmonary embolism, is a common disease that frequently recurs. Recurrence can be prevented by anticoagulants, but this comes at the risk of bleeding. Therefore, assessment of the risk of recurrence is important to balance the risks and benefits of anticoagulant treatment. This review briefly outlines what is currently known about the epidemiology of recurrent venous thrombosis, and focuses in more detail on potential new risk factors for venous recurrence. The general implications of these findings in patient management are discussed.
\end{abstract}

Key words: Recurrent venous thrombosis; Epidemiology; Risk factors

\section{Introduction}

Pulmonary embolism and deep vein thrombosis are part of the spectrum of a single disease defined as venous thrombosis, which occurs in approximately 1-2 per 1000 persons per year (1). Approximately $30 \%$ of the apparently isolated episodes of pulmonary embolism are associated with silent deep vein thrombosis (2). In patients presenting symptoms of deep vein thrombosis, the frequency of silent pulmonary embolism ranges between 40 and $50 \%$ (3). The short-term death rate due to pulmonary embolism is 3-6\% $(1,4)$. A common complication of deep vein thrombosis is the post-thrombotic syndrome, which occurs in up to $50 \%$ of patients (5).

Venous thrombosis can recur and its recurrence rate (after stopping anticoagulant treatment) is $25 \%$ within 5 years $(6,7)$. Although many clinical and laboratory risk factors for first venous thrombosis have been established (8), only a few of these risk factors are known to play a role in the prediction of a recurrent event (Table 1) $(9,10)$. Recurrent venous thrombosis usually leads to a decision for life-long anticoagulant treatment, which substantially increases long-term health care costs. Furthermore, anticoagulation is associated with serious potential side effects such as major bleeding. Therefore, efforts are required to reduce the risk of recurrent venous thrombosis while minimizing the use of anticoagulant treatment. This requires the identification of factors associated with recurrence.

This review briefly outlines what is currently known about the epidemiology of recurrent venous thrombosis, and also focuses in more detail on potential new risk factors for venous recurrence. The general implications of these findings in patient management are discussed.

\section{Currently known risk factors for the recurrence of venous thrombosis}

The risk of thrombosis recurrence is especially high in patients in whom the initial venous thrombosis was unprovoked (i.e., the event occurred in the absence of transitory risk factors including surgery, hospitalization, immobilization, and oral contraceptive use or pregnancy/puerperium) (1113). It is important to keep in mind that, as long as the risk factor that caused the thrombosis is present the increased risk remains. This is especially important in patients with active cancer, who have a high risk of recurrence even during vitamin $\mathrm{K}$ antagonist treatment $(14,15)$. Women who had a first venous thrombotic event that was associated with concurrent oral contraceptive use are at high risk for recurrence when they do not refrain from oral contraceptives after

Correspondence: D.D. Ribeiro, Divisão de Hemostasia, Departamento de Hematologia, Universidade Federal de Minas Gerais, Av. Alfredo Balena, 101, 31270-901 Belo Horizonte, MG, Brasil. Fax +55-31-3409-9397. E-mail: ddribeiro@terra.com.br

Received June 29, 2011. Accepted December 1, 2011. Available online December 23, 2011. Published January 16, 2012. 
Table 1. Risk factors for recurrent venous thrombosis.

\begin{tabular}{llll}
\hline Genetic & Acquired & Environmental & Mixed or not well established \\
\hline Antithrombin deficiency & Malignancy & Surgery and major trauma & High factor VIII \\
Protein C deficiency & Antiphospholipid antibodies & $\begin{array}{l}\text { Pregnancy and puerperium } \\
\text { Oral contraceptives }\end{array}$ & High D-dimer \\
Protein S deficiency & & Factor V Leiden \\
& & Hormone replacement therapy & Prothrombin G20210A \\
& & Prolonged immobilization & Infection \\
& & Gender \\
& & Obesity \\
& & Past risk situations \\
& & Residual vein thrombosis \\
& & Mode of first event type \\
\hline
\end{tabular}

the event occurred. This is illustrated by the LETS-follow-up study where $40 \%$ of women continued, started or restarted oral contraceptive use during follow-up. These women had a 4.6 -fold $(95 \% \mathrm{Cl}=1.9-11.5)$ higher recurrence rate than women in the same age group (16-48 years) who stopped using oral contraceptives after their first event, and who were not pregnant during follow-up [recurrence rate of 48.8/1000 person-years $(95 \% \mathrm{Cl}=24.3-87.2)$ for oral contraceptive use versus $10.5 / 1000$ person-years $(95 \% \mathrm{Cl}=4.5-20.7)$ for no hormonal contraception or pregnancy] (16).

After discontinuation of anticoagulant therapy the annual risk of recurrence among patients with antiphospholipid syndrome may be as high as 50 to $67 \%$, especially during the first few months (17). Most clinicians therefore opt to treat venous thrombosis patients with strict diagnostic criteria for antiphospholipid syndrome, (18) with long-term anticoagulant treatment $(11,19)$.

\section{Potential new risk factors for venous recurrence}

\section{General characteristics \\ Sex}

Recent studies have shown that men have a 2-4-fold higher risk of recurrent venous thrombosis than women $(16,20,21)$. The reason why men would be at higher risk of recurrent venous thrombosis than women is unknown. It could be explained by an imbalance of environmental risk factors for venous thrombosis in men compared to women, for example, due to hormonal risk factors to which only women are exposed. As oral contraceptives are discouraged after first venous thrombosis and thromboprophylaxis is often recommended in women during pregnancy or puerperium after a first event $(22,23)$, women may have a lower thrombosis potential level for recurrence than men in whom environmental risk factors are less often associated with risk for a first venous thrombosis (24). Some studies indeed suggested that the lower risk of recurrent venous thrombosis in women could be explained by a reduced rate of recurrence after venous thrombosis associated with oral contraceptive use or pregnancy (24-26). However, a recent meta-analysis concluded that the lower risk of recurrent venous thrombosis in women could not be fully accounted for by a reduced rate of recurrence after venous thrombosis associated with oral contraceptive use or pregnancy (27). Whether or not male gender in itself is a potential factor in the development for recurrent venous thrombosis is still unclarified; nevertheless, it is a clear predictor of an increased recurrence risk.

\section{Age}

Although age is a strong risk factor for first venous thrombosis, it seems to have no effect on the risk of recurrence. Some authors have reported a slightly increased risk (hazard ratio 1.36 per increase in each decade of age) $(28,29)$, and others found no relationship $(4,6,30)$, or even a decreased risk with ageing (31). In routine clinical practice, age at first venous thrombosis is usually taken into consideration when a patient is counseled regarding duration of anticoagulant treatment. Some clinicians are reluctant to treat elderly patients with anticoagulants for a long period of time because they consider risk of bleeding rather than risk of venous recurrence as the determinant for duration of anticoagulation. Others, in contrast, are hesitant to recommend extended anticoagulation to younger patients because they assume that these patients may have a low recurrence risk. Many younger individuals dislike long-term anticoagulation simply because of the prospect of a long-time medical treatment. According to previous findings, the risk of recurrence is similar for younger and older patients. Therefore, age at first venous thrombosis should not matter when determining how long patients with thrombosis should receive anticoagulation, provided their risk of bleeding is low (30).

\section{Overweight/obesity}

Obesity is a risk factor for first and recurrent venous thrombosis $(32,33)$. It is not completely understood why 
obesity predisposes to venous thrombosis. People with overweight or obesity tend to be more immobile, which may lead to clot formation through stasis. It is also possible that these individuals acquire a prothrombotic state. Indeed, studies have shown an association between increase in body mass index (BMI) and factor VIII levels (34), which is a risk factor for venous thrombosis (35). Adipose tissue may contribute to enhanced coagulation by direct tissue factor production, but hypercoagulability could also be due to direct effects of adipose tissue on the hepatic synthesis of coagulation factors $(36,37)$. Another explanation is that estrogen levels are higher in obese men and women due to an increased conversion from androgen to estrogen in adipose tissue (38). As estrogens and progestagens are prothrombotic (39), this may also be a possible pathway. A third explanation may be that obesity is considered to be a chronic low-grade inflammatory state, which may result in increases of clotting factors leading to venous thrombosis (37). It seems plausible that weight loss can reduce the risk of recurrent venous thrombosis (30), although prospective follow-up studies on this issue have not been performed.

\section{Specific aspects related to thrombosis Risk situations for venous thrombosis that occurred in the past but did not result in venous thrombosis}

Some patients with first venous thrombosis may have experienced many risk situations for thrombosis during their life time without actually developing it, while others may have experienced few of such risk situations and then developed venous thrombosis idiopathically or after a single provoked risk factor. In a previous study, we hypothesized that those who had 'survived' many risk situations without developing venous thrombosis would have a lower recurrence risk after a first event (40). In this Brazilian cohort, risk situations for venous thrombosis that occurred in the past but did not result in venous thrombosis at that time were noted in $66 \%$ of patients. Although the high rate of positive responders to this question provided a large group to evaluate our hypothesis, the risk of patients with unprovoked venous thrombosis with or without past risk situations was still 3-fold higher than the risk of those who had a provoked risk factor present at time of first venous thrombosis. Hence, asking patients with venous thrombosis about risk situations for venous thrombosis that took place long before their first thrombotic event seems to be of little value for predicting if an individual patient has a low risk for thrombosis recurrence.

\section{Infections}

A recent prospective population-based cohort study showed that elevated $\mathrm{C}$-reactive protein (CRP) levels were associated with an increased risk of venous thrombosis (41). Interestingly, it was shown that this risk was highest when CRP levels were elevated during the period just before the onset of venous thrombosis. This latter finding supports the hypothesis that the coagulation system can be stimulated by transient infection (42), which has also been suggested by experimental studies (43). Two retrospective cohort studies showed that patients with a transient infection such as urinary tract infection or pneumonia had a 2- to 3 -fold increased risk of acute venous thrombosis $(44,45)$. Thus, in the presence of a transient infection, a clinician could decide to withhold anticoagulant treatment after 3-6 months in a person with a first venous thrombosis at the time of such an episode of infection or inflammation. This approach is supported by the study by Baglin et al. (46) and is recommended by the ACCP Guidelines, based on a low risk of thrombotic recurrence when the provoking risk factor is known and transient (11). However, because infections may also lead to transient periods of immobilization or hospitalization, this increased risk could also be explained by a concurrent period of immobilization leading to venous stasis that ultimately leads to thrombosis. Whether common transient or inflammatory diseases should therefore be considered as provoking risk factors for venous thrombosis is uncertain.

\section{Thrombophilia}

Thrombophilia can be identified in about half of all patients presenting venous thrombosis, and appears to provide at least a partial explanation for a previously poorly explained disease. Over the past decades, testing has increased tremendously for various indications, but whether the results of such tests aid the clinical management of patients has not been settled (47). There is weak evidence that testing for thrombophilia could improve the risk prediction for venous thrombosis recurrence. Those with positive tests have at most a small increase in the risk of recurrence $(7,9,48)$. The association between natural anticoagulant deficiencies (protein C, protein S, antithrombin) and an increased risk of venous recurrence has been established $(49,50)$, but the clinical relevance of this association is unknown. There is no proof that screening for thrombophilia helps patients with regard to treatment of the acute event or for prevention of recurrence $(7,46,51)$.

\section{Mode of first event presentation}

The mode of presentation of venous thrombosis, as deep vein thrombosis or pulmonary embolism, could predict the likelihood and type of recurrence. In a recent meta-analysis on this issue, the risk for recurrence as pulmonary embolism was 3.1-fold greater in patients presenting previous symptomatic pulmonary embolism than in patients with previous proximal deep vein thrombosis. Patients with proximal deep vein thrombosis had a 4.8-fold higher cumulative recurrence rate than those with distal deep vein thrombosis (52). High risk of pulmonary embolism at recurrence in patients with an initial pulmonary embolism has been shown repeatedly (53-55). It is not clear why patients with pulmonary embolism have a higher chance of recurrence than patients with 
deep vein thrombosis (54-57). However, given that the risk of fatal pulmonary embolism is two to four times higher in patients with symptomatic pulmonary embolism and the risk of chronic pulmonary embolism and pulmonary hypertension is 15 to 20 times more likely when the pulmonary embolism is recurrent $(56,58,59)$, the mode of initial presentation appears to be an important factor in determining the duration of anticoagulant therapy in individual patients after a first episode of venous thrombosis. The current recommendation for anticoagulation duration is already shorter for patients with distal venous thrombosis (11). However, more studies are needed in order to support different recommendations for the management of pulmonary embolism and proximal deep vein thrombosis.

\section{Residual vein thrombosis}

The presence of sequelae in the area affected by venous thrombosis is a possible risk factor for recurrence (60). Two interventional studies used residual vein thrombosis to guide the duration of anticoagulation treatment after unprovoked proximal deep vein thrombosis $(61,62)$. Tailoring the duration of oral anticoagulant therapy on the basis of findings of repeated leg vein ultrasonography reduced the risk for recurrent venous thrombosis by $35 \%$ compared to the administration of conventional, fixed time treatment without an appreciable increase in hemorrhagic risk (61). However, many patients without sequelae relapsed; therefore, this assessment reduces but does not exclude the possibility to misclassify patients as being at low risk for recurrence (61). Because there are currently no uniformly acknowledged criteria for the definition of vein decimalization, any clinical decision made on the basis of residual vein thrombosis assessment can only be premature $(9,12,63)$.

\section{D-dimer testing}

D-dimer levels have been used as a predictive test for recurrence of venous thrombosis when remaining high after 30 days of discontinuation of oral anticoagulation (64). An Italian Multicenter Interventional Trial (PROLONG) evaluated adult patients after a first event of unprovoked venous thrombosis who were treated for at least three months with oral anticoagulants. The relative risk of events (recurrence or bleeding) was four times higher in patients with abnormal D-dimer levels who had not resumed anticoagulation compared to those who restarted the anticoagulation (64). The risk of recurrence in patients with unprovoked venous thrombosis and normal D-dimer levels was similar to that of patients with a first provoked episode of venous thrombosis (65). In the PROLONG II study, published in 2010, the Italian investigators reported that repeated testing of
D-dimer concentrations after withdrawal of anticoagulation treatment following a first episode of unprovoked venous thrombosis could help establish the optimum duration of treatment (66). Although these results are encouraging, it should be remembered that the positive predictive value of a high D-dimer concentration regarding recurrent venous thrombosis is low and therefore not very helpful for clinical decision making (67). The measurement of D-dimer might be more useful in identifying patients at low risk of recurrence in whom the risk of bleeding during long-term anticoagulation might be higher than the risk of recurrence after stopping treatment.

\section{Risk assessment in patients with unprovoked first venous thrombosis}

A recently introduced approach for the assessment of risk for recurrent venous thrombosis is the combination of clinical characteristics of the patients (i.e., location of the thrombus, gender, or age) with laboratory or imaging tests. Rodger et al. (31) identified that a combination of 2 or more of the following risk factors in women: absence of symptoms suggestive of post-thrombotic syndrome, D-dimer concentration during anticoagulation treatment $<250 \mathrm{ng} / \mathrm{mL}$, $\mathrm{BMI}<30 \mathrm{~kg} / \mathrm{m}^{2}$, and age $<65$ years, could be predictive of a low recurrence risk. No combination of predictors identified a low-risk group of men. Following the same principles as those of the study by Rodger et al. (31), Eichinger et al. (68) developed a nomogram that can be used to calculate risk scores and expected cumulative recurrence rates. The variables used were: gender, location of initial venous thrombosis and D-dimer levels in individual patients. Both prediction models need to be validated before they can be used in clinical care.

In summary, prevention of recurrent venous thrombosis will be more profitable if it becomes possible both to identify more precisely those persons who are at risk of recurrent venous thrombosis and to quantify the risk to which they are exposed. Consideration of the discussed new risk factors for recurrence may allow us a more optimal use of prophylactic strategies against recurrent venous thrombosis. More research on this topic is needed before conclusions can be drawn.

\section{Acknowledgments}

W.M. Lijfering is a Postdoc of the Netherlands Heart Foundation (\#2011T012) and D.D. Ribeiro is the recipient of support from the CAPES/NUFFIC project. 


\section{References}

1. Naess IA, Christiansen SC, Romundstad P, Cannegieter SC, Rosendaal FR, Hammerstrom J. Incidence and mortality of venous thrombosis: a population-based study. J Thromb Haemost 2007; 5: 692-699.

2. Turkstra F, Koopman MM, Buller HR. The treatment of deep vein thrombosis and pulmonary embolism. Thromb Haemost 1997; 78: 489-496.

3. Meignan M, Rosso J, Gauthier H, Brunengo F, Claudel $S$, Sagnard L, et al. Systematic lung scans reveal a high frequency of silent pulmonary embolism in patients with proximal deep venous thrombosis. Arch Intern Med 2000; 160: 159-164.

4. Hansson PO, Sorbo J, Eriksson H. Recurrent venous thromboembolism after deep vein thrombosis: incidence and risk factors. Arch Intern Med 2000; 160: 769-774.

5. Prandoni $P$, Lensing AW, Prins $M H$, Frulla $M$, Marchiori $A$, Bernardi E, et al. Below-knee elastic compression stockings to prevent the post-thrombotic syndrome: a randomized, controlled trial. Ann Intern Med 2004; 141: 249-256.

6. Prandoni P, Noventa F, Ghirarduzzi A, Pengo V, Bernardi $E$, Pesavento R, et al. The risk of recurrent venous thromboembolism after discontinuing anticoagulation in patients with acute proximal deep vein thrombosis or pulmonary embolism. A prospective cohort study in 1,626 patients. Haematologica 2007; 92: 199-205.

7. Christiansen SC, Cannegieter SC, Koster T, Vandenbroucke JP, Rosendaal FR. Thrombophilia, clinical factors, and recurrent venous thrombotic events. JAMA 2005; 293: 23522361.

8. Lijfering WM, Rosendaal FR, Cannegieter SC. Risk factors for venous thrombosis - current understanding from an epidemiological point of view. Br J Haematol 2010; 149: 824-833.

9. Kyrle PA, Rosendaal FR, Eichinger S. Risk assessment for recurrent venous thrombosis. Lancet 2010; 376: 20322039.

10. Zhu T, Martinez I, Emmerich J. Venous thromboembolism: risk factors for recurrence. Arterioscler Thromb Vasc Biol 2009; 29: 298-310.

11. Kearon C, Kahn SR, Agnelli G, Goldhaber S, Raskob GE, Comerota AJ. Antithrombotic therapy for venous thromboembolic disease: American College of Chest Physicians Evidence-Based Clinical Practice Guidelines (8th Edition). Chest 2008; 133: 454S-545S.

12. Kearon $\mathrm{C}$. Extended anticoagulation for unprovoked venous thromboembolism: a majority of patients should be treated. J Thromb Thrombolysis 2011; 31: 295-300.

13. Prandoni $P$, Villalta $S$, Bagatella $P$, Rossi L, Marchiori A, Piccioli $A$, et al. The clinical course of deep-vein thrombosis. Prospective long-term follow-up of 528 symptomatic patients. Haematologica 1997; 82: 423-428.

14. Mandala M, Falanga A, Roila F. Venous thromboembolism in cancer patients: ESMO Clinical Practice Guidelines for the management. Ann Oncol 2010; 21 (Suppl 5): v274-v276.

15. Louzada ML, Majeed H, Dao V, Wells PS. Risk of recurrent venous thromboembolism according to malignancy characteristics in patients with cancer-associated thrombosis: a systematic review of observational and intervention studies. Blood Coagul Fibrinolysis 2011; 22: 86-91.
16. Christiansen SC, Lijfering WM, Helmerhorst FM, Rosendaal FR, Cannegieter SC. Sex difference in risk of recurrent venous thrombosis and the risk profile for a second event. $J$ Thromb Haemost 2010; 8: 2159-2168.

17. Schulman S, Svenungsson E, Granqvist S. Anticardiolipin antibodies predict early recurrence of thromboembolism and death among patients with venous thromboembolism following anticoagulant therapy. Duration of Anticoagulation Study Group. Am J Med 1998; 104: 332-338.

18. Miyakis S, Lockshin MD, Atsumi T, Branch DW, Brey RL, Cervera $\mathrm{R}$, et al. International consensus statement on an update of the classification criteria for definite antiphospholipid syndrome (APS). J Thromb Haemost 2006; 4: 295306.

19. Pengo V, Ruffatti A, Legnani C, Gresele P, Barcellona D, Erba N, et al. Clinical course of high-risk patients diagnosed with antiphospholipid syndrome. J Thromb Haemost 2010; 8: 237-242.

20. Cosmi B, Legnani C, Tosetto A, Pengo V, Ghirarduzzi A, Testa S, et al. Sex, age and normal post-anticoagulation Ddimer as risk factors for recurrence after idiopathic venous thromboembolism in the Prolong study extension. J Thromb Haemost 2010; 8: 1933-1942.

21. Kyrle PA, Minar E, Bialonczyk C, Hirschl M, Weltermann A, Eichinger $\mathrm{S}$. The risk of recurrent venous thromboembolism in men and women. N Engl J Med 2004; 350: 2558-2563.

22. De Stefano V, Martinelli I, Rossi E, Battaglioli T, Za T, Mannuccio Mannucci $P$, et al. The risk of recurrent venous thromboembolism in pregnancy and puerperium without antithrombotic prophylaxis. Br J Haematol 2006; 135: 386391.

23. Bates SM, Greer IA, Pabinger I, Sofaer S, Hirsh J. Venous thromboembolism, thrombophilia, antithrombotic therapy, and pregnancy: American College of Chest Physicians Evidence-Based Clinical Practice Guidelines (8th Edition). Chest 2008; 133: 844S-886S.

24. Lijfering WM, Veeger NJ, Middeldorp S, Hamulyak K, Prins $\mathrm{MH}$, Buller HR, et al. A lower risk of recurrent venous thrombosis in women compared with men is explained by sex-specific risk factors at time of first venous thrombosis in thrombophilic families. Blood 2009; 114: 2031-2036.

25. Cushman M, Glynn RJ, Goldhaber SZ, Moll S, Bauer KA, Deitcher $S$, et al. Hormonal factors and risk of recurrent venous thrombosis: the prevention of recurrent venous thromboembolism trial. J Thromb Haemost 2006; 4: 21992203.

26. Pengo V, Prandoni P. Sex and anticoagulation in patients with idiopathic venous thromboembolism. Lancet 2006; 368: 342-343.

27. Douketis J, Tosetto A, Marcucci M, Baglin T, Cosmi B, Cushman $\mathrm{M}$, et al. Risk of recurrence after venous thromboembolism in men and women: patient level meta-analysis. BMJ 2011; 342: d813.

28. Labropoulos N, Jen J, Jen H, Gasparis AP, Tassiopoulos AK. Recurrent deep vein thrombosis: long-term incidence and natural history. Ann Surg 2010; 251: 749-753.

29. Heit JA, Mohr DN, Silverstein MD, Petterson TM, O'Fallon WM, Melton LJ III. Predictors of recurrence after deep vein thrombosis and pulmonary embolism: a population-based 
cohort study. Arch Intern Med 2000; 160: 761-768.

30. Eischer L, Eichinger S, Kyrle PA. Age at first venous thromboembolism and risk of recurrence: a prospective cohort study. Medicine 2009; 88: 366-370.

31. Rodger MA, Kahn SR, Wells PS, Anderson DA, Chagnon I, Le Gal G, et al. Identifying unprovoked thromboembolism patients at low risk for recurrence who can discontinue anticoagulant therapy. CMAJ 2008; 179: 417-426.

32. Abdollahi M, Cushman M, Rosendaal FR. Obesity: risk of venous thrombosis and the interaction with coagulation factor levels and oral contraceptive use. Thromb Haemost 2003; 89: 493-498.

33. Eichinger S, Hron G, Bialonczyk C, Hirschl M, Minar E, Wagner $\mathrm{O}$, et al. Overweight, obesity, and the risk of recurrent venous thromboembolism. Arch Intern Med 2008; 168 : 1678-1683.

34. Lijfering WM, Christiansen SC, Naess IA, Hammerstroem $\mathrm{J}$, van Hylckama Vlieg A, Rosendaal FR, et al. The risk of venous thrombosis related to increase body mass index is mediated by factor VIII induced APC-resistance. Blood (ASH Annual Meeting Abstracts) 2009; 114: 453 (Abstract).

35. Bank I, Libourel EJ, Middeldorp S, Hamulyak K, van Pampus EC, Koopman MM, et al. Elevated levels of FVIII:C within families are associated with an increased risk for venous and arterial thrombosis. J Thromb Haemost 2005; 3: 79-84.

36. Faber DR, DE Groot PG, Visseren FL. Role of adipose tissue in haemostasis, coagulation and fibrinolysis. Obes Rev 2009; 10: 554-563.

37. Darvall KA, Sam RC, Silverman SH, Bradbury AW, Adam DJ. Obesity and thrombosis. Eur J Vasc Endovasc Surg 2007; 33: 223-233.

38. Hautanen A. Synthesis and regulation of sex hormonebinding globulin in obesity. Int $\mathrm{J}$ Obes Relat Metab Disord 2000; 24 (Suppl 2): S64-S70.

39. Middeldorp S, Meijers JC, van den Ende AE, van Enk A, Bouma BN, Tans G, et al. Effects on coagulation of levonorgestrel- and desogestrel-containing low dose oral contraceptives: a cross-over study. Thromb Haemost 2000; 84: 4-8.

40. Ribeiro DD, Lijfering WM, Barreto SM, Silva IB, Chalup MM, Rosendaal FR, et al. Past provoking venous thrombosis risk situations on the risk of a recurrent thrombotic event: a cohort study. Thromb Res 2011; 128: 227-232.

41. Quist-Paulsen P, Naess IA, Cannegieter SC, Romundstad PR, Christiansen SC, Rosendaal FR, et al. Arterial cardiovascular risk factors and venous thrombosis: results from a population-based, prospective study (the HUNT 2). Haematologica 2010; 95: 119-125.

42. Tichelaar YI, Knol HM, Mulder AB, Kluin-Nelemans JC, Lijfering WM. Association between deep vein thrombosis and transient inflammatory signs and symptoms: a case-control study. J Thromb Haemost 2010; 8: 1874-1876.

43. Riewald M, Ruf W. Science review: role of coagulation protease cascades in sepsis. Crit Care 2003; 7: 123-129.

44. Samama MM. An epidemiologic study of risk factors for deep vein thrombosis in medical outpatients: the Sirius study. Arch Intern Med 2000; 160: 3415-3420.

45. Smeeth L, Cook C, Thomas S, Hall AJ, Hubbard R, Vallance P. Risk of deep vein thrombosis and pulmonary embolism after acute infection in a community setting. Lancet 2006; 367: 1075-1079.

46. Baglin T, Luddington R, Brown K, Baglin C. Incidence of recurrent venous thromboembolism in relation to clinical and thrombophilic risk factors: prospective cohort study. Lancet 2003; 362: 523-526.

47. Middeldorp S, van Hylckama V. Does thrombophilia testing help in the clinical management of patients? Br J Haematol 2008; 143: 321-335.

48. Lijfering WM, Middeldorp S, Veeger NJ, Hamulyak K, Prins $\mathrm{MH}$, Buller HR, et al. Risk of recurrent venous thrombosis in homozygous carriers and double heterozygous carriers of factor V Leiden and prothrombin G20210A. Circulation 2010; 121: 1706-1712.

49. Brouwer JL, Lijfering WM, Ten Kate MK, Kluin-Nelemans $\mathrm{HC}$, Veeger NJ, van der Meer J. High long-term absolute risk of recurrent venous thromboembolism in patients with hereditary deficiencies of protein $\mathrm{S}$, protein $\mathrm{C}$ or antithrombin. Thromb Haemost 2009; 101: 93-99.

50. Lijfering WM, Brouwer JL, Veeger NJ, Bank I, Coppens M, Middeldorp S, et al. Selective testing for thrombophilia in patients with first venous thrombosis: results from a retrospective family cohort study on absolute thrombotic risk for currently known thrombophilic defects in 2479 relatives. Blood 2009; 113: 5314-5322.

51. Kearon C, Julian JA, Kovacs MJ, Anderson DR, Wells P, Mackinnon B, et al. Influence of thrombophilia on risk of recurrent venous thromboembolism while on warfarin: results from a randomized trial. Blood 2008; 112: 4432-4436.

52. Baglin T, Douketis J, Tosetto A, Marcucci M, Cushman M, Kyrle $P$, et al. Does the clinical presentation and extent of venous thrombosis predict likelihood and type of recurrence? A patient-level meta-analysis. J Thromb Haemost 2010; 8: 2436-2442.

53. Eichinger S, Weltermann A, Minar E, Stain M, Schonauer V, Schneider B, et al. Symptomatic pulmonary embolism and the risk of recurrent venous thromboembolism. Arch Intern Med 2004; 164: 92-96.

54. Jimenez D, Diaz G, Marin E, Vidal R, Sueiro A, Yusen RD. The risk of recurrent venous thromboembolism in patients with unprovoked symptomatic deep vein thrombosis and asymptomatic pulmonary embolism. Thromb Haemost 2006; 95: $562-566$

55. Douketis JD, Kearon C, Bates S, Duku EK, Ginsberg JS. Risk of fatal pulmonary embolism in patients with treated venous thromboembolism. JAMA 1998; 279: 458-462.

56. Murin S, Romano PS, White RH. Comparison of outcomes after hospitalization for deep venous thrombosis or pulmonary embolism. Thromb Haemost 2002; 88: 407-414.

57. Agnelli G, Prandoni P, Becattini C, Silingardi M, Taliani MR, Miccio $\mathrm{M}$, et al. Extended oral anticoagulant therapy after a first episode of pulmonary embolism. Ann Intern Med 2003; 139: $19-25$

58. Siddique RM, Siddique MI, Connors AF Jr, Rimm AA. Thirtyday case-fatality rates for pulmonary embolism in the elderly. Arch Intern Med 1996; 156: 2343-2347.

59. White RH, Zhou H, Murin S. Death due to recurrent thromboembolism among younger healthier individuals hospitalized for idiopathic pulmonary embolism. Thromb Haemost 2008; 99: 683-690.

60. Prandoni P, Lensing AW, Prins MH, Bernardi E, Marchiori A, Bagatella $P$, et al. Residual venous thrombosis as a predictive factor of recurrent venous thromboembolism. Ann Intern Med 2002; 137: 955-960.

61. Prandoni P, Prins MH, Lensing AW, Ghirarduzzi A, Ageno W, Imberti $\mathrm{D}$, et al. Residual thrombosis on ultrasonography to 
guide the duration of anticoagulation in patients with deep venous thrombosis: a randomized trial. Ann Intern Med 2009; 150: 577-585.

62. Siragusa S, Malato A, Anastasio R, Cigna V, Milio G, Amato $C$, et al. Residual vein thrombosis to establish duration of anticoagulation after a first episode of deep vein thrombosis: the Duration of Anticoagulation based on Compression UItraSonography (DACUS) study. Blood 2008; 112: 511-515.

63. Tan M, Mos IC, Klok FA, Huisman MV. Residual venous thrombosis as predictive factor for recurrent venous thromboembolim in patients with proximal deep vein thrombosis: a sytematic review. Br J Haematol 2011; Doi: 10.1111/j.13652141.2011.08578.

64. Palareti G, Cosmi B, Legnani C, Tosetto A, Brusi C, lorio A, et al. D-dimer testing to determine the duration of anticoagulation therapy. N Engl J Med 2006; 355: 1780-1789.

65. Verhovsek M, Douketis JD, Yi Q, Shrivastava S, Tait RC, Ba- glin T, et al. Systematic review: D-dimer to predict recurrent disease after stopping anticoagulant therapy for unprovoked venous thromboembolism. Ann Intern Med 2008; 149: 481490, W94.

66. Cosmi B, Legnani C, Tosetto A, Pengo V, Ghirarduzzi A, Testa S, et al. Usefulness of repeated D-dimer testing after stopping anticoagulation for a first episode of unprovoked venous thromboembolism: the PROLONG II prospective study. Blood 2010; 115: 481-488.

67. Le Gal G, Bounameaux H. d-Dimer testing to predict recurrence risk in venous thromboembolism: looking for a useful threshold: a rebuttal. J Thromb Haemost 2004; 2: 16701672.

68. Eichinger S, Heinze G, Jandeck LM, Kyrle PA. Risk assessment of recurrence in patients with unprovoked deep vein thrombosis or pulmonary embolism: the Vienna prediction model. Circulation 2010; 121: 1630-1636. 